OPEN ACCESS

Edited by:

Amy Rasley,

Lawrence Livermore National Laboratory, USA

Reviewed by:

Hridayesh Prakash, University of Hyderabad, India Diego A. Vargas-Inchaustegui, National Cancer Institute, USA

*Correspondence:

Diana Bahia

dianabahia@hotmail.com

Specialty section:

This article was submitted to Microbial Immunology, a section of the journal

Frontiers in Microbiology

Received: 23 November 2015 Accepted: 02 February 2016

Published: 24 February 2016

Citation:

Soares-Silva M, Diniz FF, Gomes GN

and Bahia D (2016)

The Mitogen-Activated Protein Kinase (MAPK) Pathway: Role in Immune

Evasion by Trypanosomatids.

Front. Microbiol. 7:183.

doi: 10.3389/fmicb.2016.00183

\section{The Mitogen-Activated Protein Kinase (MAPK) Pathway: Role in Immune Evasion by Trypanosomatids}

\author{
Mercedes Soares-Silva ${ }^{1}$, Flavia F. Diniz ${ }^{1}$, Gabriela N. Gomes ${ }^{1}$ and Diana Bahia',2* \\ ${ }^{1}$ Departamento de Biologia Geral, Instituto de Ciências Biológicas, Universidade Federal de Minas Gerais, Minas Gerais, \\ Brazil, ${ }^{2}$ Departamento de Microbiologia, Imunologia e Parasitologia, Escola Paulista de Medicina, Universidade Federal de \\ São Paulo, São Paulo, Brazil
}

Leishmania spp. and Trypanosoma cruzi are the causative agents of leishmaniasis and Chagas disease, respectively, two neglected tropical diseases that affect about 25 million people worldwide. These parasites belong to the family Trypanosomatidae, and are both obligate intracellular parasites that manipulate host signaling pathways and the innate immune system to establish infection. Mitogen-activated protein kinases (MAPKs) are serine and threonine protein kinases that are highly conserved in eukaryotes, and are involved in signal transduction pathways that modulate physiological and pathophysiological cell responses. This mini-review highlights existing knowledge concerning the mechanisms that Leishmania spp. and T. cruzi have evolved to target the host's MAPK signaling pathways and highjack the immune response, and, in this manner, promote parasite maintenance in the host.

Keywords: MAP kinase, Trypanosoma cruzi, Leishmania, immune evasion of parasites, cellular signaling

\section{INTRODUCTION}

Leishmania spp. and Trypanosoma cruzi are protozoan parasites of the Trypanosomatida order (Kent, 1980) and Trypanosomatidae family (Doflein, 1901). They are the etiological agents of leishmaniasis and Chagas disease, respectively, and are transmitted by the bite of infected sandflies (leishmaniasis) or through triatomine bug feces (Chagas disease). Both Leishmania spp. and T. cruzi have complex life cycles comprising diverse developing forms that alternate between the insect vector and the vertebrate host. Leishmania spp. promastigotes and amastigotes preferentially infect phagocytic cells of vertebrates, while T. cruzi metacyclic trypomastigotes, blood trypomastigotes and amastigotes are able to infect both phagocytic and non-phagocytic cells (Tanowitz et al., 1992; Alexander et al., 1999; Ferreira et al., 2012).

Although the persistence of Leishmania spp. and T. cruzi within a host depends on several factors, the manipulation of host signal transduction pathways involved in the modulation of the immune response is probably one of the most commonly used mechanisms by parasites. In this mini-review, we will focus on the mechanisms that Leishmania spp. and T. cruzi use to subvert mitogen-activated protein kinase (MAPK) signaling pathways-more specifically, extracellularsignal-regulated kinase (ERK), and p38 MAPK-that are highly relevant in the context of the regulation of the immune response against intracellular parasites. 


\section{MAPK PATHWAYS}

Mitogen-activated protein kinases are protein kinases that phosphorylate their own dual serine and threonine residues (autophosphorylation), or those found on their substrates, to activate or de-activate their target (Johnson and Lapadat, 2002; Peti and Page, 2013). Accordingly, MAPKs regulate important cellular processes such as proliferation, stress responses, apoptosis and immune defense (Dong et al., 2002; Liu et al., 2007; Arthur and Ley, 2013). MAPKs are ubiquitously expressed and evolutionarily conserved in eukaryotes (Kyriakis and Avruch, 2001; Kyriakis and Avruch, 2012; Peti and Page, 2013). The activation of a MAPK cascade occurs in a module of consecutive phosphorylations, i.e., after a previous stimulus, each MAPK is phosphorylated by an upstream MAPKs. A MAPK module comprises a MAP3K that activates a MAP2K, which then, in turn, activates a MAPK (Pimienta and Pascual, 2007; Turjanski, Vaqué and Gutkind, 2007; Johnson, 2011; Kyriakis and Avruch, 2012; Peti and Page, 2013). MAPK phosphorylation events can be inactivated by MAPK protein phosphatases (MKPs) that dephosphorylate both phosphothreonine and phosphotyrosine residues on MAPKs (Liu et al., 2007; Pimienta and Pascual, 2007; Zhang and Dong, 2007).

There are three well-known MAPK pathways in mammalian cells (Figure 1): the ERK1/2, the c-JUN N-terminal kinase 1, 2 and $3(\mathrm{JNK} 1 / 2 / 3)$, and the p38 MAPK $\alpha, \beta, \delta$, and $\gamma$ pathways. ERK, JNK, and p38 isoforms are grouped according to their activation motif, structure and function (Owens and Keyse, 2007; Raman et al., 2007; Zhang and Dong, 2007). ERK1/2 is activated in response to growth factors, hormones and proinflammatory stimuli, while JNK1/2/3 and p38 MAPK $\alpha, \beta, \delta$, and $\gamma$ are activated by cellular and environmental stresses, in addition to proinflammatory stimuli (Owens and Keyse, 2007; Kyriakis and Avruch, 2012; Figure 1).

\section{ERK AND P38 MAPK PATHWAYS}

The classical activation of ERK1 and ERK2 isoforms is initiated by the binding of a ligand to a receptor tyrosine kinase (RTK) at the plasma membrane (PM), followed by activation of the small G-protein, Ras. In turn, Ras recruits and activates the serine/threonine protein kinase, Raf, a MAP3K, which activates the MAP2K, MEK, that, in turn, phosphorylates the MAPK, ERK1/2, at both threonine and tyrosine residues within the TEY motif (Kolch, 2000; Chambard et al., 2007; Shaul and Seger, 2007; Knight and Irving, 2014). The Ras/Raf/MEK/ERK1/2 pathway can be deactivated by dual-specificity MAPK phosphatases (MKPs). For example, MKP2/4 dephosphorylates ERK1/2, but can also deactivate other MAPKs while MKP3 and MKP-X are specific to ERK (Owens and Keyse, 2007). The tyrosine phosphatase, SHP2, also acts on this signaling pathway by activating the G-protein, Ras (Zhang et al., 2004; Matozaki et al., 2009; Figure 1A).

Both stress and cytokines activate p38 MAPK isoforms that play an important role in inflammatory responses (Johnson and Lapadat, 2002; Yang et al., 2014), despite each isoform being encoded by different genes and showing different tissue expression patterns (Cuadrado and Nebreda, 2010). As with ERK isoforms, p38 MAPKs are also sequentially activated. A canonical activation occurs when, in response to stress or cytokines, a MAP3K, such as MEKK1, ASK1, or TAK1, is activated by TRAF [TNF (tumor necrosis factor) receptorassociated factor] $2 / 3 / 6$ or by Rho proteins. In turn, the MAP3K phosphorylates a MAP2K, either MKK3 or MKK6, that then phosphorylates the TGY motif of p38 isoforms (Cuenda and Rousseau, 2007; Cuadrado and Nebreda, 2010; Figure 1B). The p38 MAPKs $\alpha, \beta, \delta$ and $\gamma$, are dephosphorylated by several dual-specificity protein phosphatases, such as $\mathrm{MPK} 2 / 4$, that can also deactivate ERK. The phosphatases, MPK5/7, can also dephosphorylate JNK and p38, while MPK1 exhibits a higher specificity for p38 (Owens and Keyse, 2007; Salojin and Oravecz, 2007).

\section{MAPKS AND THE IMMUNE SYSTEM}

Many pathogens target host intracellular signaling pathways, including MAPK pathways, to inhibit immune responses (Roy and Mocarski, 2007; Arthur and Ley, 2013). The immune response is one of several key functions regulated by MAPKs, with the production of immunomodulatory cytokines, such as TNF $\alpha$, interleukin (IL)-1, IL-10, and IL-12, induced by the activation of p38 MAPK, JNK, and ERK pathways (Dong et al., 2002; Arthur and Ley, 2013). The regulatory cytokines, IL-12 and IL-10, produced by specialized dendritic and macrophage cells, play an important role in the coordination of the immune response since IL-12 modulates the development of a Th1 response, which protects the host against intracellular parasites, and IL-10 promotes a Th2 response, which provides protection against extracellular infectious agents (Romagnani, 2006).

The production of $\mathrm{IL}-12$ is regulated by p38 MAPK and, consequently, is involved in the induction of a Th1 response (Jackson et al., 2010; Arthur and Ley, 2013). Upon p38 MAPK activation and IL-12 production, Th cell differentiation is guided into a Th1-type cell that releases pro-inflammatory cytokines such as IL- 2 , IFN- $\gamma$, and TNF- $\alpha / \beta$ (Romagnani, 2006). Such cytokines mediate the immune response by acting to kill intracellular pathogens such as the protozoans, Leishmania spp. and T. cruzi (Beiting, 2014).

Conversely, the ERK1/2 pathway modulates the production of IL-10 (Chang et al., 2012) that induces Th cell differentiation into a Th2-type. In this manner, Th2 cells regulate the host's humoral immune response by releasing anti-inflammatory cytokines, such as IL-4, IL-5, IL-9, and IL-13, that are involved in allergic reactions and the elimination of extracellular pathogens (Mosmann et al., 2009). Furthermore, IL-10 can also act as a negative regulator of inflammation to prevent tissue damage (Haddad et al., 2003; Romagnani, 2006; Guilliams et al., 2009; Bosschaerts et al., 2010). 


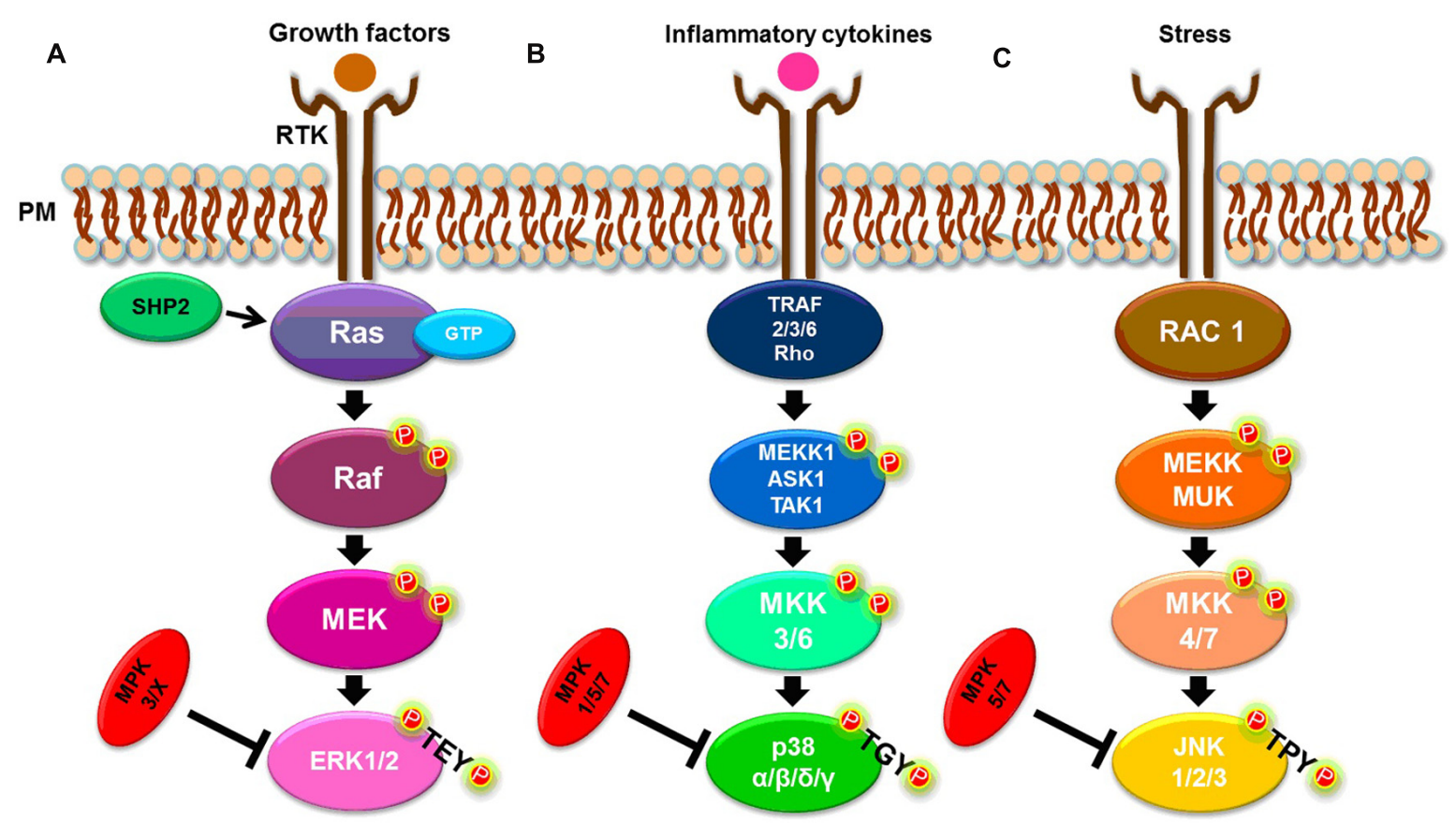

FIGURE 1 | Simplified MAPK signaling pathways. (A) ERK1/2 pathway. (B) p38 $\alpha, \beta, \delta$, and $\gamma$ pathways. (C) JNK 1,2 , and 3 pathways. See text for details.

\section{HOST IMMUNE RESPONSE SUBVERSION BY PROTOZOAN PARASITES}

Protozoan parasites use many varied tactics to avoid and/or subvert the host's immune response, with the adoption of an intracellular lifestyle one the first mechanisms (Sacks and Sher, 2002). Other successful strategies employed by such pathogens to circumvent the immune system include: the expression of specific parasite antigens on the surface of infected cells to prevent recognition by immune cells (Sacks and Sher, 2002), the subversion of $\mathrm{T}$ cell responses by interfering with cytokine production (Engwerda et al., 2014), and the avoidance of direct killing by the complement system (Ouaissi and Ouaissi, 2005).

To protect an organism against protozoan intracellular infection, its immune system needs to identify and eliminate the parasite, but, at the same time, also needs to be balanced in order to minimize or avoid self-inflicted tissue damage (Dent, 2002). Phagocytosis is the primary mechanism used by the immune system in its response to intracellular parasites. This mechanism, mainly promoted by macrophages, depends on parasite recognition and is enhanced by opsonization and the complement system (Stafford et al., 2002). Leishmania spp. and T. cruzi escape from the host's complement system using different strategies. T. cruzi produces glycoproteins that inhibit C3b/C4b (gp160), factor B (gp58) and molecules that accelerate the decay of the C3 pathway. In contrast, Leishmania spp. adapt their membrane to prevent the insertion of C5b-C9. This species also produces a surface metalloproteinase, gp63, and a lipophosphoglycan (LPG) that cleave C3b, abrogating complement-mediated lysis (Sacks and Sher, 2002; Ouaissi and Ouaissi, 2005). Leishmania gp63 can also activate the complement system, leading to parasite opsonization and increased uptake by host macrophages in a highly advantageous mechanism that allows both forms of this parasite (promastigote and amastigote) to replicate inside host macrophages (Stafford et al., 2002; Gómez and Olivier, 2010).

Although phagocytosis is the first mechanism activated in immune protection, the induction of a Th1-type response is the most effective reaction against intracellular protozoans. The promotion of such an inflammatory response leads to the successful elimination of these parasites due to the release and intense activity of pro-inflammatory cytokines and mediators (Jankovic et al., 2001; Stafford et al., 2002; Guilliams et al., 2009; Bosschaerts et al., 2010; Beiting, 2014; Engwerda et al., 2014). As outlined previously, the generation of Th1 and Th2 responses is regulated by IL-12 and IL-10 cytokines, respectively, which are modulated by the host's intracellular MAPK signaling pathways (Dong et al., 2002; Arthur and Ley, 2013). So, by acting on the MAPK signaling pathway, intracellular protozoan parasites can switch the production of regulatory cytokines from IL-12 to IL-10 to prevent the formation of an inflammatory response (Jankovic et al., 2001; Stafford et al., 2002; ZambranoVilla et al., 2002; Guilliams et al., 2009). In this way, T. cruzi and Leishmania spp. impair the development of a Th1 response to favor a Th2-type response. The mechanisms used by these 
parasites to deregulate the immune response will be briefly reviewed below.

\section{Leishmania spp. SUBVERT THE MAPK PATHWAY BY ACTIVATING ERK1/2 TO INCREASE IL-10 AND DOWN-REGULATE IL-12}

Leishmania spp. parasites use several strategies to survive inside host cells after infection. The methods employed by these parasites to subvert the host's immune defense systems include: (i) an intracellular stage in their life cycle, allowing them protection against humoral anti-leishmanicidal products; (ii) the suppression of the synthesis of reactive oxygen intermediates (ROI) or reactive nitrogen intermediates (RNI); (iii) the inhibition of antigen presentation by repressing the gene expression of major histocompatibility complex (MHC) class II, interfering with antigen loading, or by sequestering/highjacking the MHC II molecule or antigen; (iv) the subversion of host cellular signaling pathways such as STAT, PI3K/AKT, and MAPK; and (v) the modulation of host cytokines to avoid $\mathrm{T}$ cell differentiation and thus prevent the formation of a Th1-type immune response (Bogdan and Röllinghoff, 1998; Olivier et al., 2005; Liese et al., 2008; Martinez and Petersen, 2014).

To undermine the production of regulatory inflammatory cytokines and prevent the formation of a Th1-type immune response, Leishmania parasites target the MAPK signaling pathway, which is responsible for regulating the production of IL-12 (p38) and IL-10 (ERK 1/2) in macrophages and dendritic cells. By this means, Leishmania spp. promote switching from IL12 to IL-10 production, consequently altering the formation of a Th1 response to Th2, and leading to parasite prevalence in the host (Ghalib et al., 1995; Olivier et al., 2005; Bhardwaj et al., 2010; Shadab and Ali, 2011).

Rub et al. (2009) have shown that Leishmania spp. often act upon the CD40/MAPK pathway. Expressed mainly on macrophages and dendritic cells, CD40 is an important costimulatory molecule involved in the differentiation of Th cells to a Th1-type, reflecting how CD40 induces the production of IL-12 (O'Sullivan and Thomas, 2003) by the activation of MAPK pathway members (Bhardwaj et al., 2010). In their study, Rub et al. (2009) showed that L. major triggered cholesterol depletion, and, in doing so, prevented CD40 reallocation to skew the CD40 signaling pathway from p38 and IL-12 to ERK1/2 and IL-10 production. As a consequence, this event led to an increased IL-10 production. Taken together, these events favored a parasite burden and confirmed that the CD40/MAPK pathway was important for L. major subversion of the host's immune response. However, the specific mechanism surrounding augmented IL-10 production remained unknown until Srivastava et al. (2011) and Khan et al. (2014) noted the participation of phosphatases in this process. Srivastava et al. (2011) demonstrated that in L. major infection, the phosphatases, MKP-1 and MKP-3, were differentially expressed. L. major induced the upregulation of MKP-1 (p38 high affinity phosphatase) and downregulation of MKP-3 (ERK1/2 high affinity phosphatase) to skew CD40 signaling toward the ERK1/2 pathway, favoring infection. Khan et al. (2014) demonstrated that the phosphotyrosine phosphatase, SHP-1, functioned in a similar manner and acted on Syk and Lyn (ERK1/2 and p38 MAPK activators, respectively). In a CD40 dose-dependent manner, SHP-1 modulates CD40-induced phosphorylation of p38 MAPK and ERK1/2 to favor ERK1/2-dependent IL-10 expression and parasite survival (Figure 2). Xin et al. (2008) and Boggiatto et al. $(2009,2014)$ also demonstrated the importance of the CD40/MAPK signaling pathway in L. amazonensis infection. L. amazonensis upregulated ERK1/2 in dendritic cells, increased IL-10 production and prevented the expression of CD40 and IL-12p40 (one of the subunits of IL-12), leading to the limited activation of dendritic cells and a deficient Th1-type response.

Extracellular-signal-regulated kinase $1 / 2$ activation by Leishmania spp., associated with parasite persistence and IL12 down-regulation, was also seen for L. amazonensis (Xin et al., 2008; Martinez and Petersen, 2014) and for L. donovani. Infection by L. donovani also led to the suppression of p38 MAPK and increased IL-10 production (Chandra and Naik, 2008; Shadab and Ali, 2011). Interestingly, treatment of L. donovani-infected macrophages with an immunoprophylactic glycolipid, arabinosylated lipoarabinomannan (AraLAM) isolated from Mycobacterium smegmatis, activated p38 MAPK with a concomitant abrogation of ERK1/2 phosphorylation. Furthermore, the production of IL-12 (Bhattacharya et al., 2011) and IFN $\gamma$ responsiveness were restored (Chowdhury et al., 2015). Exploitation of host phosphatases can also be seen in L. donovani infection: Nandan and Reiner (2005) showed that L. donovani activates the phosphotyrosine phosphatase, SHP-1 that correlates with parasite survival.

Gp63 and LPG can also modulate the host MAPK signaling pathway and the production of cytokines. Gp63 acts on both p38 and the phosphotyrosine phosphatase SHP-1. To subvert MAPK signaling, gp63 of $L$. major promastigotes leads to a p38 inhibition in fibroblasts by mediating the proteolysis of TAK-1-binding protein-1 (TAB1), a p38 regulator (Halle et al., 2009). Gp63 of both L. major and L. mexicana amastigotes and promastigotes activates SHP-1 in macrophages in a cleavage-dependent manner leading to p38 down-regulation (Gomez et al., 2009; Abu-Dayyeh et al., 2010). Gp63-mediated inactivation of p38 could consequently inhibit IL-12 production. Conversely, the LPG of L. braziliensis and $L$. infantum also activates ERK1/2, but abrogates not only IL-12 production, but also that of IL-10 (Ibraim et al., 2013). Further studies are needed to understand the mechanisms by which LPG modulates MAPK and IL-12 production in an IL-10-independent manner. L. mexicana LPG can also manipulate the MAPK pathway and inhibit IL-12 but this seems to be due to the impairment of NFKB translocation caused by LPG (Cameron et al., 2004; Argueta-Donohué et al., 2008; Table 1A). 


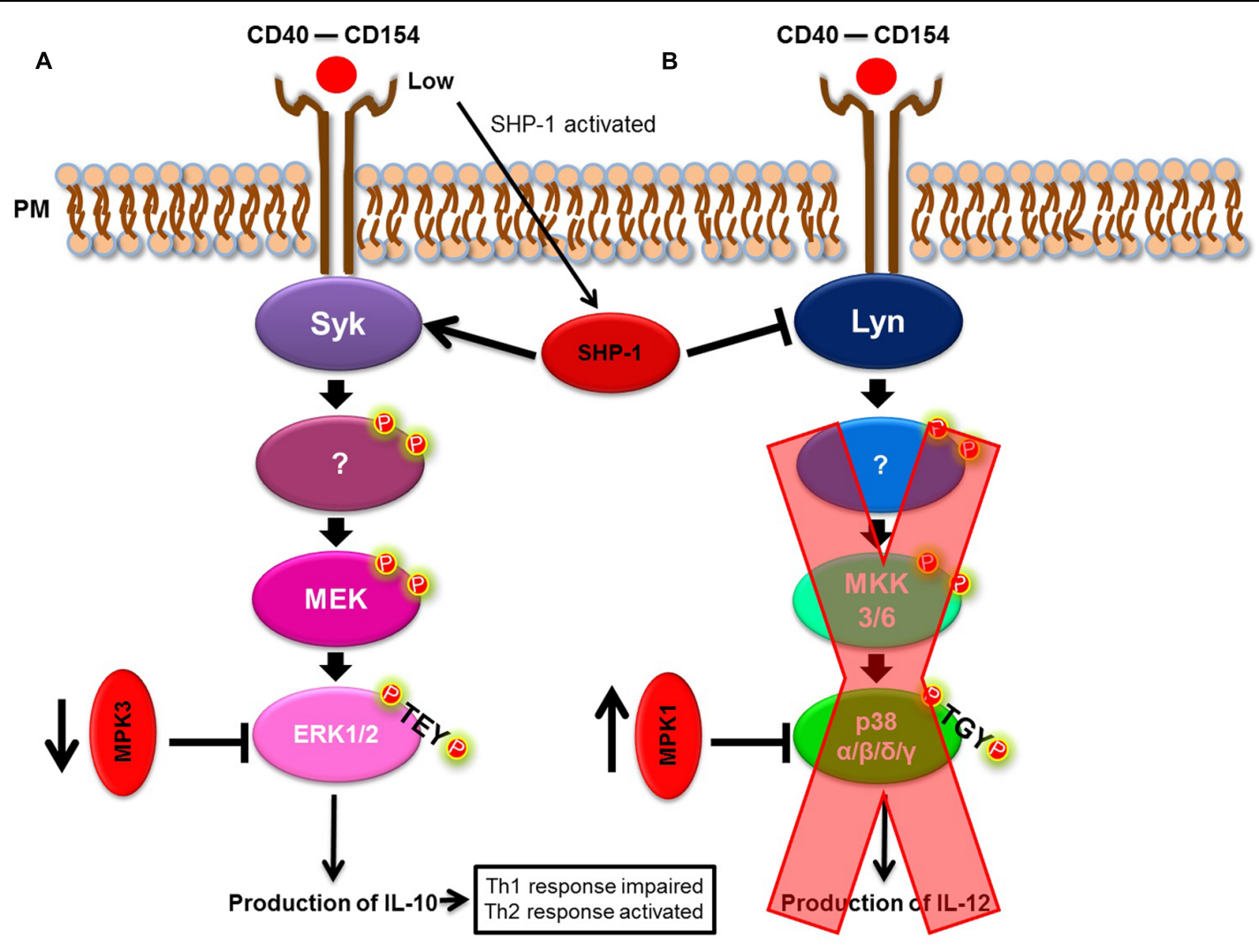

FIGURE 2 | Leishmania spp. model of immune modulation targeting the p38/ERK1/2 MAPK pathway. (A) CD40/ERK1/2 pathway. (B) CD40/p38 MAPK pathway. Leishmania spp. skew the CD40/MAPK signaling pathway, from p38 to ERK1/2, to favor IL-10 production.

\section{Trypanosoma cruzi TRIGGERS MOLECULES TO REGULATE THE MAPK PATHWAY AND CYTOKINE PRODUCTION}

The mechanisms by which $T$. cruzi evades the host's immune response by acting on the MAPK pathway have been poorly studied and are therefore incompletely understood. However, it is well established that upon cell invasion, T. cruzi begins to subvert signaling pathways and to use host molecules to favor its entry and survival inside host cells. For instance, T. cruzi extracellular amastigotes (EAs) recruit both host protein kinase D1 (PKD1) and cortactin to induce PKD1 autophosphorylation and cortactin activation by ERK, leading to the recruitment of host actin that allows parasite entry into HeLa cells (Bonfim-Melo et al., 2015). T. cruzi, as well as Leishmania spp., is able to induce: (i) ERK1/2, but not p38 MAPK, activation in macrophages and dendritic cells (Mukherjee et al., 2004); and (ii) increased IL-10 and decreased IL-12 production (Poncini et al., 2008). These effects impair the formation of an efficient Th1 inflammatory response (Alba Soto et al., 2003, 2010) to allow parasite evasion of the host immune response.

Some T. cruzi molecules are released and activate Toll-like receptors (TLRs), such as TLR2, TLR4, or TLR9, in dendritic cells and macrophages (Tarleton, 2007). This leads to the activation of p38 MAPK and the production of IL-12, favoring an inflammatory response (Ropert et al., 2001; Terrazas et al., 2011). This model is supported by the observations of Terrazas et al. (2011) who showed that dendritic cells exposed to T. cruzi antigens (TcAgs) and TLR ligands induced p38 phosphorylation that was dependent on TcAg-macrophage migration inhibitory factor (MIF) synergism. This led to the enhancement of IL-12 production, thus promoting a Th1-type response (Terrazas et al., 2011).

However, despite the activation of a pro-inflammatory immune response by some parasite molecules, it is well known that several other molecules of such pathogens act against the host's infected cells and signaling pathways, subverting the host's immune response against the parasite (Ouaissi et al., 1995; Hovsepian et al., 2011; Castillo et al., 2013; Ruiz Díaz et al., 2015).

One of the proteins released by T. cruzi that disrupts the host's immune response is Tc52. A protein of $52 \mathrm{kDa}$, Tc52 is composed of two homologous domains sharing significant homology with glutathione S-transferases (Schöneck et al., 1994), and exhibits both immunomodulatory and virulence roles (Ouaissi et al., $1995,2002 \mathrm{a})$. When localized in the cytoplasm, a $28 \mathrm{kDa}$ peptide fragment derived from the C-terminal portion of Tc52 (Borges et al., 2003) induces the Tc52-mediated suppression of $\mathrm{T}$ cell proliferation, and exerts mitogen-dependent cytokine and chemokine-like activities. Thus, this peptide modulates genes that 
TABLE 1 | Trypanosomatids-released proteins and their action on MAPK pathway in macrophages and T cells.

\begin{tabular}{|c|c|c|c|c|}
\hline \multicolumn{5}{|c|}{ (A) Leishmania spp. proteins } \\
\hline Protein & $\begin{array}{l}\text { MAPK Target on } \\
\text { macrophages }\end{array}$ & Mechanism & Target on $\mathrm{T}$ cells & Reference \\
\hline gp63 & p38 MAPK & $\begin{array}{l}\text { Cleavage-dependent activation of } \\
\text { SHP-1 leading to p38 inactivation and, } \\
\text { presumably, inhibition of IL-12 }\end{array}$ & $\mathrm{IL}-12$ & $\begin{array}{l}\text { Gomez et al., 2009; } \\
\text { Abu-Dayyeh et al., } 2010\end{array}$ \\
\hline LPG & ERK & $\begin{array}{l}\text { Activation of ERK abrogating both IL-10 } \\
\text { and IL-12 production }\end{array}$ & IL-10 and IL-12 & $\begin{array}{l}\text { Feng et al., 1999; Ibraim et al., } \\
2013\end{array}$ \\
\hline \multicolumn{5}{|c|}{ (B) Trypanosoma cruzi proteins } \\
\hline Protein & $\begin{array}{l}\text { MAPK Target on } \\
\text { macrophages }\end{array}$ & Mechanism & Target on $\mathrm{T}$ cells & Reference \\
\hline Tc52 & p38 or ERK & $\begin{array}{l}\text { Mitogen-dependent modulation of } \\
\text { genes that encode IL-10 and IL-12 } \\
\text { leading to increased IL-10 secretion } \\
\text { and inhibition of IL-12 }\end{array}$ & $\mathrm{IL}-10$ and $\mathrm{IL}-12$ & $\begin{array}{l}\text { Ouaissi et al., 2002b; Borges } \\
\text { et al., 2003; Ouaissi and } \\
\text { Ouaissi, } 2005\end{array}$ \\
\hline $\mathrm{AgC10}$ & p38 & Inhibition of p38 and IL-12 & $\mid \mathrm{L}-12$ & $\begin{array}{l}\text { De Diego et al., 1997; Alcaide } \\
\text { and Fresno, } 2004\end{array}$ \\
\hline $\begin{array}{l}\text { GPIs and } \\
\text { GPI-anchored } \\
\text { mucins }\end{array}$ & ERK & $\begin{array}{l}\text { Activation of ERK } 1 / 2 \text { upon treatment } \\
\text { with GPIs and GPI-anchored mucins } \\
\text { associated to IL-12 decrease }\end{array}$ & $\mid \mathrm{L}-12$ & Ropert et al., 2001 \\
\hline TS & ERK & $\begin{array}{l}\text { TS activates ERK and stimulates IL-10 } \\
\text { secretion }\end{array}$ & $\mid \mathrm{L}-10$ & $\begin{array}{l}\text { Chuenkova and Pereira, 2001; } \\
\text { Ruiz Díaz et al., } 2015\end{array}$ \\
\hline
\end{tabular}

encode IL-10 and IL-12, leading to increased IL-10 secretion and thereby inhibiting IL-12 (Ouaissi et al., 2002b; Ouaissi and Ouaissi, 2005). Moreover, the events outlined above are probably mediated by MAPKs.

Other proteins related to immune modulation in T. cruzi infection are the glycosylphosphatidylinositol (GPI)-anchored mucins and trans-sialidases (TS). AgC10, a GPI-anchored mucin of $40-50 \mathrm{kDa}$, inhibits TNF and IL-12 secretion in a p38 MAPK inhibition-dependent manner, impairing the formation of a Th1 response (De Diego et al., 1997; Alcaide and Fresno, 2004). Ropert et al. (2001) reported that ERK1/2 activation was associated with a decrease in IL-12 in macrophages treated with T. cruzi GPI and GPI-mucins, corroborating the participation of these proteins in modulating the host's immune response. However, they also showed that GPIs and GPI-anchored mucins could activate p38 MAPK later than ERK1/2, thus increasing IL12 synthesis and generating an opposing effect in the regulation of the immune response by promoting a Th1 response (Ropert et al., 2001). T. cruzi TS have been linked to ERK1/2 activation (Chuenkova and Pereira, 2001). Recently, Ruiz Díaz et al. (2015) confirmed the role of TS in IL-10-stimulated secretion, leading to an imbalance of the Th1 cell response toward an Th2 phenotype (Table 1B). However, despite current knowledge concerning the strategies used by $T$. cruzi to subvert the host's immune response, the precise mechanisms by which this occurs remain unknown.

\section{CONCLUSION}

The MAPK signaling pathway, responsible for regulating the production of Th1-and Th2-type responses, is targeted by trypanosomatids to modulate the host's immune response in order to favor parasite replication and survival. The mechanisms whereby Leishmania spp. skew the MAPK signaling pathway to subvert cytokine production and switch a Th1 to a Th2 response are well known compared to those for $T$. cruzi. Leishmania parasites often target the CD40/MAPK pathway, activating ERK1/2 to increase and decrease IL-10 and IL-12 production, respectively. In comparison, the strategy used by T. cruzi is to trigger molecules to subvert MAPK ERK1/2 and p38 pathways and thus modulate cytokine production. Further studies are required to increase our understanding of the intriguing mechanisms by which T. cruzi manipulates the host's immune response.

\section{AUTHOR CONTRIBUTIONS}

MS-S, FD and GG contributed equally to the writing of the review. DB conceived and wrote the review.

\section{ACKNOWLEDGMENTS}

The authors are indebted to Prof. Dr. Erika Suzuki Toledo (Escola Paulista de Medicina, Universidade Federal de São Paulo) for her critical revision of the manuscript and valuable comments. $\mathrm{DB}$ is the recipient of a CNPq fellowship. MS is the recipient of a FAPEMIG fellowship. The authors wish to gratefully acknowledge the financial support of FAPEMIG (APQ-01674-14) and FAPESP (07/50551-2). The authors would also like to thank BioMed Proofreading (http://www.biomedproofreading.com/). 


\section{REFERENCES}

Abu-Dayyeh, I., Hassani, K., Westra, E. R., Mottram, J. C., and Olivier, M. (2010). Comparative study of the ability of Leishmania mexicana Promastigotes and amastigotes to alter macrophage signaling and functions. Infect. Immun. 78, 2438-2445. doi: 10.1128/IAI 00812-819,

Alba Soto, C. D., Mirkin, G. A., Solana, M. E., and González Cappa, S. M. (2003). Trypanosoma cruzi infection modulates in vivo expression of major histocompatibility complex class II molecules on antigen-presenting cells and T-cell stimulatory activity of dendritic cells in a strain-dependent manner. Infect. Immun. 71, 1194-1199. doi: 10.1128/IAI.71.3.1194-1199.2003

Alba Soto, C. D., Solana, M. E., Poncini, C. V., Pino-Martinez, A. M., Tekiel, V., and González-Cappa, S. M. (2010). Dendritic cells devoid of IL-10 induce protective immunity against the protozoan parasite Trypanosoma cruzi. Vaccine 28, 7407-7413. doi: 10.1016/j.vaccine.2010.08.105

Alcaide, P., and Fresno, M. (2004). AgC10, a mucin from Trypanosoma cruzi, destabilizes TNF and cyclooxygenase- 2 mRNA by inhibiting mitogen-activated protein kinase p38. Eur. J. Immunol. 34, 1695-1704. doi: 10.1002/eji.200324660

Alexander, J., Satoskar, A. R., and Russell, D. G. (1999). Leishmania species: models of intracellular parasitism. J. Cell Sci. 112, 2993.

Argueta-Donohué, J., Carrillo, N., Valdés-Reyes, L., Zentella, A., AguirreGarcía, M., Becker, I., et al. (2008). Leishmania mexicana: participation of NF-кB in the differential production of IL-12 in dendritic cells and monocytes induced by lipophosphoglycan (LPG). Exp. Parasitol. 120, 1-9. doi: 10.1016/j.exppara.2008.04.002

Arthur, J. S. C., and Ley, S. C. (2013). Mitogen-activated protein kinases in innate immunity. Nat. Rev. Immunol. 13, 679-692. doi: 10.1038/nri3495

Beiting, D. P. (2014). Protozoan parasites and type I interferons: a cold case reopened. Trends Parasitol. 30, 491-498. doi: 10.1016/j.pt.2014.07.007

Bhardwaj, S., Srivastava, N., Sudan, R., and Saha, B. (2010). Leishmania interferes with host cell signaling to devise a survival strategy. J. Biomed. Biotechnol. 2010, 1-13. doi: 10.1155/2010/109189

Bhattacharya, P., Gupta, G., Majumder, S., Adhikari, A., Banerjee, S., Halder, K., et al. (2011). Arabinosylated lipoarabinomannan skews Th2 phenotype towards th1 during leishmania infection by chromatin modification: involvement of MAPK signaling. PLoS ONE 6:e24141. doi: 10.1371/journal.pone.0024141

Bogdan, C., and Röllinghoff, M. (1998). The immune response to Leishmania: mechanisms of parasite control and evasion. Int. J. Parasitol. 28, 121-134. doi: 10.1016/S0020-7519(97)00169-0

Boggiatto, P. M., Jie, F., Ghosh, M., Gibson-Corley, K. N., Ramer-Tait, A. E., Jones, D. E., et al. (2009). Altered dendritic cell phenotype in response to leishmania amazonensis amastigote infection is mediated by MAP kinase. ERK. Am. J. Pathol. 174, 1818-1826. doi: 10.2353/ajpath.2009.080905

Boggiatto, P. M., Martinez, P. A., Pullikuth, A., Jones, D. E., Bellaire, B., Catling, A., et al. (2014). Targeted extracellular signal-regulated kinase activation mediated by Leishmania amazonensis requires MP1 scaffold. Microbes Infect. 16, 328-336. doi: 10.1016/j.micinf.2013.12.006

Bonfim-Melo, A., Zanetti, B. F., Ferreira, É. R., Vandoninck, S., Han, S. W., Van Lint, J., et al. (2015). T rypanosoma cruzi extracellular amastigotes trigger the protein kinase D1-cortactin-actin pathway during cell invasion. Cell. Microbiol. 17, 1797-1810. doi: $10.1111 / \mathrm{cmi} .12472$

Borges, M., Da Silva, A. C., Sereno, D., and Ouaissi, A. (2003). Peptide-based analysis of the amino acid sequence important to the immunoregulatory function of Trypanosoma cruzi Tc52 virulence factor. Immunology 109, 147155. doi: 10.1046/j.1365-2567.2003.01637.x

Bosschaerts, T., Guilliams, M., Stijlemans, B., Morias, Y., Engel, D., Tacke, F., et al. (2010). Tip-DC development during parasitic infection is regulated by IL-10 and requires CCL2/CCR2, IFN- $\gamma$ and MyD88 signaling. PLoS Pathog. 6:e1001045. doi: 10.1371/journal.ppat.1001045

Cameron, P., McGachy, A., Anderson, M., Paul, A., Coombs, G. H., Mottram, J. C., et al. (2004). Inhibition of lipopolysaccharide-induced macrophage IL-12 production by Leishmania mexicana amastigotes: the role of cysteine peptidases and the NF-kappaB signaling pathway. J. Immunol. 173, 3297-3304.

Castillo, C., Villarroel, A., Duaso, J., Galanti, N., Cabrera, G., Maya, J. D., et al. (2013). Phospholipase C gamma and ERK1/2 Mitogen Activated Kinase Pathways are differentially modulated by Trypanosoma cruzi during tissue invasion in human placenta. Exp. Parasitol. 133, 12-17. doi: 10.1016/j.exppara.2012.10.012
Chambard, J. C., Lefloch, R., Pouysségur, J., and Lenormand, P. (2007). ERK implication in cell cycle regulation. Biochim. Biophys. Acta 1773, 1299-1310. doi: 10.1016/j.bbamcr.2006.11.010

Chandra, D., and Naik, S. (2008). Leishmania donovani infection downregulates TLR2-stimulated IL-12p40 and activates IL-10 in cells of macrophage/monocytic lineage by modulating MAPK pathways through a contact-dependent mechanism. Clin. Exp. Immunol. 154, 224-234. doi: 10.1111/j.1365-2249.2008.03741.x

Chang, C.-F., D’Souza, W. N., Ch'en, I. L., Pages, G., Pouyssegur, J., and Hedrick, S. M. (2012). Polar opposites: Erk direction of CD4 T cell subsets. J. Immunol. 189, 721-731. doi: 10.4049/jimmunol.1103015

Chowdhury, B. P., Bandyopadhyay, S., Das, S., Majumder, S., Jha, M. K., Majumdar, S. B., et al. (2015). The host-protective effect of arabinosylated lipoarabinomannan against Leishmania donovani infection is associated with restoration of IFN- $\gamma$ responsiveness. PLoS ONE 10:e0117247. doi: 10.1371/journal.pone.0117247

Chuenkova, M. V., and Pereira, M. A. (2001). The T. cruzi trans-sialidase induces PC12 cell differentiation via MAPK/ERK pathway. Neuroreport 4, 3715-3718. doi: 10.1097/00001756-200112040-00022

Cuadrado, A., and Nebreda, A. R. (2010). Mechanisms and functions of p38 MAPK signalling. Biochem. J. 429, 403-417. doi: 10.1042/BJ20100323

Cuenda, A., and Rousseau, S. (2007). p38 MAP-kinases pathway regulation, function and role in human diseases. Biochim. Biophys. Acta 1773, 1358-1375. doi: 10.1016/j.bbamcr.2007.03.010

De Diego, J., Punzón, C., Duarte, M., and Fresno, M. (1997). Alteration of macrophage function by a Trypanosoma cruzi membrane mucin. J. Immunol. $15,4983-4989$.

Dent, L. A. (2002). For better or worse: common determinants influencing health and disease in parasitic infections, asthma and reproductive biology. J. Reproduct. Immunol. 57, 255-272. doi: 10.1016/S0165-0378(02)00017-7

Dong, C., Davis, R. J., and Flavell, R. A. (2002). MAP kinases in the immune response. Annu. Rev. Immunol. 20, 55-72. doi: 10.1146/annurev.immunol.20.091301.131133

Engwerda, C. R., Ng, S. S., and Bunn, P. T. (2014). The regulation of $\mathrm{CD}^{4+}$ $\mathrm{T}$ Cell responses during protozoan infections. Front. Immunol. 5:498. doi: 10.3389/fimmu.2014.00498

Feng, G., Goodridge, H. S., Harnett, M. M., Wei, X., Nikolaev, A. V., Higson, A. P., et al. (1999). Extracellular signal-related kinase (ERK) and p38 mitogen-activated protein (MAP) kinases differentially regulate the lipopolysaccharide-mediated induction of inducible nitric oxide synthase and IL-12 in macrophages: Leishmania phosphoglycans subvert macrophage IL-12 production by targeting ERK MAP kinase. J. Immunol. 163, 6403-6412.

Ferreira, É. R., Bonfim-Melo, A., Mortara, R. A., and Bahia, D. (2012). Trypanosoma cruzi extracellular amastigotes and host cell signaling: more pieces to the puzzle. Front. Immunol. 3:3. doi: 10.3389/fimmu.2012.00363

Ghalib, H. W., Whittle, J. A., Kubin, M., Hashim, F. A., El-Hassan, A. M., Grabstein, K. H., et al. (1995). IL-12 enhances Th1-type responses in human Leishmania donovani infections. J. Immunol. 154, 4623-4629.

Gomez, M. A., Contreras, I., Hallé, M., Tremblay, M. L., Mcmaster, R. W., and Olivier, M. (2009). Leishmania GP63 alters host signaling through cleavage-activated protein tyrosine phosphatases. Sci Signal 29, ra582. doi: $10.1126 /$ scisignal.2000213

Gómez, M. A., and Olivier, M. (2010). Proteases and phosphatases during Leishmania-macrophage interaction: paving the road for pathogenesis. Virulence 1, 314-318. doi: 10.4161/viru.1.4.12194

Guilliams, M., Movahedi, K., Bosschaerts, T., VandenDriessche, T., Chuah, M. K., Herin, M., et al. (2009). IL-10 Dampens TNF/Inducible nitric oxide synthaseproducing dendritic cell-mediated pathogenicity during parasitic infection. J. Immunol. 182, 1107-1118. doi: 10.4049/jimmunol.182.2.1107

Haddad, J. J., Saadé, N. E., and Safieh-Garabedian, B. (2003). Interleukin-10 and the regulation of mitogen-activated protein kinases: ae these signalling modules targets for the anti-inflammatory action of this cytokine? Cell. Signal. 15, 255-267. doi: 10.1016/S0898-6568(02)00075-X

Halle, M., Gomez, M. A., Stuible, M., Shimizu, H., McMaster, W. R., Olivier, M., et al. (2009). The leishmania surface protease GP63 cleaves multiple intracellular proteins and actively participates in p38 mitogenactivated protein kinase inactivation. J. Biol. Chem. 284, 6893-6908. doi: 10.1074/jbc.M805861200 
Hovsepian, E., Mirkin, G. A., Penas, F., Manzano, A., Bartrons, R., and Goren, N. B. (2011). Modulation of inflammatory response and parasitism by 15 -Deoxy$\Delta$ 12,14 prostaglandin J2 in Trypanosoma cruzi-infected cardiomyocytes. Int. J. Parasitol. 41, 553-562. doi: 10.1016/j.ijpara.2010.12.002

Ibraim, I. C., de Assis, R. R., Pessoa, N. L., Campos, M. A., Melo, M. N., Turco, S. J., et al. (2013). Two biochemically distinct lipophosphoglycans from Leishmania braziliensis and Leishmania infantum trigger different innate immune responses in murine macrophages. Parasit. Vect. 6, 54. doi: 10.1186/1756-3305-6-54

Jackson, A. M., Mulcahy, L. A., Porte, J., Franks, H. A., Refaee, M., El Wang, Q., et al. (2010). Role of mitogen-activated protein kinase and PI3K pathways in the regulation of IL-12-family cytokines in dendritic cells and the generation of T H-responses. Eur. Cytok. Netw. 21, 319-328. doi: 10.1684/ecn.2010.0219

Jankovic, D., Sher, A., and Yap, G. (2001). Th1/Th2 effector choice in parasitic infection: decision making by committee. Curr. Opin. Immunol. 13, 403-409. doi: 10.1016/S0952-7915(00)00234-X

Johnson, G. L. (2011). Defining MAPK interactomes. ACS Chem. Biol. 6, 18-20. doi: $10.1021 / \mathrm{cb} 100384 \mathrm{z}$

Johnson, G. L., and Lapadat, R. (2002). Mitogen-activated protein kinase pathways mediated by ERK, JNK, and p38 protein kinases. Science 298, 1911-1912. doi: $10.1126 /$ science. 1072682

Khan, T. H., Srivastava, N., Srivastava, A., Sareen, A., Mathur, R. K., Chande, A. G., et al. (2014). SHP-1 plays a crucial role in cd40 signaling reciprocity. J. Immunol. 193, 3644-3653. doi: 10.4049/jimmunol.1400620

Knight, T., and Irving, J. A. E. (2014). Ras/Raf/MEK/ERK Pathway activation in childhood acute lymphoblastic leukemia and its therapeutic targeting. Front. Oncol. 4:160. doi: 10.3389/fonc. 2014.00160

Kolch, W. (2000). Meaningful relationships: the regulation of the Ras/Raf/MEK/ERK pathway by protein interactions. Biochem. J. 351( $\mathrm{Pt}$ 2), 289-305. doi: 10.1042/bj3510289

Kyriakis, J. M., and Avruch, J. (2001). Mammalian mitogen-activated protein kinase signal transduction pathways activated by stress and inflammation. Physiol. Rev. 81, 807-869.

Kyriakis, J. M., and Avruch, J. (2012). Mammalian MAPK signal transduction pathways activated by stress and inflammation: A 10-Year Update. Physiol. Rev. 92, 689-737. doi: 10.1152/physrev.00028.2011

Liese, J., Schleicher, U., and Bogdan, C. (2008). The innate immune response against Leishmania parasites. Immunobiology 213, 377-387. doi: 10.1016/j.imbio.2007.12.005

Liu, Y., Shepherd, E. G., and Nelin, L. D. (2007). MAPK phosphatases-regulating the immune response. Nat. Rev. Immunol. 7, 202-212. doi: 10.1038/nri2035

Martinez, P. A., and Petersen, C. A. (2014). Chronic infection by Leishmania amazonensis mediated through MAPK ERK mechanisms. Immunol. Res. 59, 153-165. doi: 10.1007/s12026-014-8535-y

Matozaki, T., Murata, Y., Saito, Y., Okazawa, H., and Ohnishi, H. (2009). Protein tyrosine phosphatase SHP-2: a roto-oncogene product that promotes Ras activation. Cancer Sci. 100, 1786-1793. doi: 10.1111/j.1349-7006.2009.01257.x

Mosmann, T. R., Kobie, J. J., Lee, F. E.-H., and Quataert, S. A. (2009). T helper cytokine patterns: defined subsets, random expression, and external modulation. Immunol. Res. 45, 173-184. doi: 10.1007/s12026-009-8098-5

Mukherjee, S., Huang, H., Petkova, S. B., Albanese, C., Pestell, R. G., Braunstein, V. L., et al. (2004). Trypanosoma cruzi infection activates extracellular signalregulated kinase in cultured endothelial and smooth muscle cells. Society 72 , 5274-5282.

Nandan, D., and Reiner, N. E. (2005). Leishmania donovani engages in regulatory interference by targeting macrophage protein tyrosine phosphatase SHP-1. Clin. Immunol. 114, 266-277. doi: 10.1016/j.clim.2004.07.017

Olivier, M., Gregory, D. J., and Forget, G. (2005). Subversion mechanisms by which leishmania parasites can escape the host immune response: a signaling point of view. Clin. Microbiol. Rev. 18, 293-305. doi: 10.1128/CMR.18.2.293305.2005

O'Sullivan, B., and Thomas, R. (2003). CD40 and dendritic cell function. Crit. Rev. Immunol. 23, 83-107. doi: 10.1615/CritRevImmunol.v23.i12.50

Ouaissi, A., Guevara-Espinoza, A., Chabe, F., Gomez-Corvera, R., and Taibi, A. (1995). A novel and basic mechanism of immunosuppression in Chagas' disease: Trypanosoma cruzi releases in vitro and in vivo a protein which induces $\mathrm{T}$ cell unresponsiveness through specific interaction with cysteine and glutathione. Immunol. Lett. 48, 221-224. doi: 10.1016/0165-2478(95)02463-8
Ouaissi, A., Guilvard, E., Delneste, Y., Caron, G., Magistrelli, G., Herbault, N., et al. (2002a). The Trypanosoma cruzi Tc52-released protein induces human dendritic cell maturation, signals via toll-like receptor 2, and confers protection against lethal infection. J. Immunol. 168, 6366-6374. doi: 10.4049/jimmunol.168.12.6366

Ouaissi, A., Ouaissi, M., and Sereno, D. (2002b). Glutathione S-transferases and related proteins from pathogenic human parasites behave as immunomodulatory factors. Immunol. Lett. 81, 159-164. doi: 10.1016/S0165-2478(02)00035-4

Ouaissi, A., and Ouaissi, M. (2005). Molecular basis of Trypanosoma cruzi and Leishmania interaction with their host(s): exploitation of immune and defense mechanisms by the parasite leading to persistence and chronicity, features reminiscent of immune system evasion strategies in cancer dis. Arch. Immunol. Ther. Exp. 53, 102-114.

Owens, D. M., and Keyse, S. M. (2007). Differential regulation of MAP kinase signalling by dual-specificity protein phosphatases. Oncogene 26, 3203-3213. doi: 10.1038/sj.onc.1210412

Peti, W., and Page, R. (2013). Molecular basis of MAP kinase regulation. Protein Sci. 22, 1698-1710. doi: 10.1002/pro.2374

Pimienta, G., and Pascual, J. (2007). Canonical and alternative MAPK signaling. Cell Cycle 6, 2628-2632. doi: 10.4161/cc.6. 21.4930

Poncini, C. V., Soto, C. D. A., Batalla, E., Solana, M. E., and Gonzalez Cappa, S. M. (2008). Trypanosoma cruzi induces regulatory dendritic cells in vitro. Infect. Immun. 76, 2633-2641. doi: 10.1128/IAI.01298-07

Raman, M., Chen, W., and Cobb, M. H. (2007). Differential regulation and properties of MAPKs. Oncogene 26, 3100-3112. doi: 10.1038/sj.onc. 1210392

Romagnani, S. (2006). Regulation of the T cell response. Clin. Exp. Allergy 36, 1357-1366. doi: 10.1111/j.1365-2222.2006.02606.x

Ropert, C., Almeida, I. C., Closel, M., Travassos, L. R., Ferguson, M. A. J., Cohen, P., et al. (2001). Requirement of mitogen-activated protein kinases and I B phosphorylation for induction of proinflammatory cytokines synthesis by macrophages indicates functional similarity of receptors triggered by glycosylphosphatidylinositol anchors from parasitic prot. J. Immunol. 166, 3423-3431. doi: 10.4049/jimmunol.166. 5.3423

Roy, C. R., and Mocarski, E. S. (2007). Pathogen subversion of cell-intrinsic innate immunity. Nat. Immunol. 8, 1179-1187. doi: 10.1038/ni1528

Rub, A., Dey, R., Jadhav, M., Kamat, R., Chakkaramakkil, S., Majumdar, S., et al. (2009). Cholesterol depletion associated with Leishmania major infection alters macrophage CD40 signalosome composition and effector function. Nat. Immunol. 10, 273-280. doi: 10.1038/ni.1705

Ruiz Díaz, P., Mucci, J., Meira, M. A., Bogliotti, Y., Musikant, D., Leguizamón, M. S., et al. (2015). Trypanosoma cruzi trans -sialidase prevents elicitation of th1 cell response via interleukin 10 and downregulates th1 effector cells. Infect. Immun. 83, 2099-2108. doi: 10.1128/IAI.00031-15

Sacks, D., and Sher, A. (2002). Evasion of innate immunity by parasitic protozoa. Nat. Rev. Immunol. 3, 1041-1047. doi: 10.1038/ni1102-1041

Salojin, K., and Oravecz, T. (2007). Regulation of innate immunity by MAPK dual-specificity phosphatases: knockout models reveal new tricks of old genes. J. Leukocyte Biol. 81, 860-869. doi: 10.1189/jlb.1006639

Schöneck, R., Plumas-Marty, B., Taibi, A., Billaut-Mulot, O., Loyens, M., GrasMasse, H., et al. (1994). Trypanosoma cruzi cDNA encodes a tandemly repeated domain structure characteristic of small stress proteins and glutathione S-transferases. Biol. Cell 80, 1-10. doi: 10.1016/0248-4900(94) 90011-6

Shadab, M., and Ali, N. (2011). Evasion of host defence by Leishmania donovani: subversion of signaling pathways. Mol. Biol. Int. 2011:343961. doi: $10.4061 / 2011 / 343961$

Shaul, Y. D., and Seger, R. (2007). The MEK/ERK cascade: From signaling specificity to diverse functions. Biochim. Biophys. Acta 1773, 1213-1226. doi: 10.1016/j.bbamcr.2006.10.005

Srivastava, N., Sudan, R., and Saha, B. (2011). CD40-modulated dualspecificity phosphatases MAPK phosphatase (MKP)-1 and MKP-3 reciprocally regulate leishmania major infection. J. Immunol. 186, 5863-5872. doi: 10.4049/jimmunol.1003957 
Stafford, J. L., Neumann, N. F., and Belosevic, M. (2002). Macrophage-mediated innate host defense against protozoan parasites. Crit. Rev. Microbiol. 28, 187 248. doi: 10.1080/1040-840291046731

Tanowitz, H. B., Kirchhoff, L. V., Simon, D., Morris, S. A., Weiss, L. M., and Wittner, M. (1992). Chagas' disease. Clin. Microbiol. Rev. 5, 400-419.

Tarleton, R. L. (2007). Immune system recognition of Trypanosoma cruzi. Curr. Opin. Immunol. 19, 430-434. doi: 10.1016/j.coi.2007.06.003

Terrazas, C. A., Huitron, E., Vazquez, A., Juarez, I., Camacho, G. M., Calleja, E. A., et al. (2011). MIF synergizes with Trypanosoma cruzi antigens to promote efficient dendritic cell maturation and IL-12 production via p38 MAPK. Int. J. Biol. Sci. 7, 1298-1310. doi: 10.7150/ijbs.7. 1298

Turjanski, A. G., Vaqué, J. P., and Gutkind, J. S. (2007). MAP kinases and the control of nuclear events. Oncogene 26, 3240-3253. doi: 10.1038/sj.onc.12 10415

Xin, L., Li, K., and Soong, L. (2008). Down-regulation of dendritic cell signaling pathways by Leishmania amazonensis amastigotes. Mol. Immunol. 45, 33713382. doi: 10.1016/j.molimm.2008.04.018

Yang, Y., Kim, S. C., Yu, T., Yi, Y., Rhee, M. H., Sung, G., and Cho, J. Y. (2014). Functional roles of p38 mitogen-activated protein kinase in macrophagemediated inflammatory responses, 2014. Med. Inflamm. 2014:352371.
Zambrano-Villa, S., Rosales-Borjas, D., Carrero, J. C., and Ortiz-Ortiz, L. (2002). How protozoan parasites evade the immune response. Trends Parasitol. 18, 272-278. doi: 10.1016/S1471-4922(02)02289-4

Zhang, S. Q., Yang, W., Kontaridis, M. I., Bivona, T. G., Wen, G., Araki, T., et al. (2004). Shp2 regulates src family kinase activity and ras/erk activation by controlling csk recruitment. Mol. Cell 13, 341-355. doi: 10.1111/j.15824934.2008.00333.x

Zhang, Y., and Dong, C. (2007). Regulatory mechanisms of mitogen-activated kinase signaling. Cell. Mol. Life Sci. 64, 2771-2789. doi: 10.1007/s00018-0077012-3

Conflict of Interest Statement: The authors declare that the research was conducted in the absence of any commercial or financial relationships that could be construed as a potential conflict of interest.

Copyright (c) 2016 Soares-Silva, Diniz, Gomes and Bahia. This is an open-access article distributed under the terms of the Creative Commons Attribution License (CC BY). The use, distribution or reproduction in other forums is permitted, provided the original author(s) or licensor are credited and that the original publication in this journal is cited, in accordance with accepted academic practice. No use, distribution or reproduction is permitted which does not comply with these terms. 